\title{
A GESTÃO E O EMPREENDEDORISMO NOS CURSOS DE FORMAÇÃO DOCENTE
}

\section{MANAGEMENT AND ENTREPRENEURSHIP IN TEACHER TRAINING COURSES}

\author{
Data do recebimento do artigo: 13/01/2014 \\ Data do aceite do artigo: 30/9/2014 \\ Data da publicação: 8/12/2014 \\ Processo de Avaliação: Double Blind Review
}

\author{
Felipe Chibás ${ }^{1}$ \\ Doutor em Ciências da Comunicação \\ Professor da ECA - Escola de Comunicação e Artes \\ USP - Universidade de São Paulo \\ Adriana Clementino \\ Doutora em Educação pela Universidade de São Paulo \\ Professora da Faculdade Instituto Paulista de Ensino
}

\section{RESUMO}

O presente artigo analisa o conceito de gestão no âmbito da educação e aborda os principais resultados obtidos a partir de uma primeira aproximação exploratória à situação das disciplinas com temas sobre gestão e empreendedorismo no contexto dos cursos de formação de professores. A pesquisa quanti-quali aqui apresentada realizou um levantamento estatístico analisando-se a grade curricular dos cursos de Pedagogia, Letras, Artes e Educação Física do Estado de São Paulo, assim como das questões da prova do ENADE referentes aos temas de gestão e empreendedorismo nesses cursos. Os resultados obtidos apontam a carência de disciplinas que lidam com o tema de Gestão e Empreendedorismo nesses cursos, tanto no que se refere à formação teórica como à falta de estimulação sistemática das competências necessárias para gerir projetos culturais ou educativos. Como consideração final, sugere-se a implementação nesses cursos de uma disciplina que reúna tais conhecimentos relativos ao termo Gestão e Empreendedorismo, e incrementar o número e complexidade das questões de Gestão e Empreendedorismo nas provas do ENADE correspondentes a estes cursos.

Palavras-chaves: Gestão e empreendedorismo. Formação docente. Instituições de Ensino Superior.

\footnotetext{
ABSTRACT

${ }^{1}$ Autor para correspondência: Escola de Comunicação e Artes da Universidade de São Paulo - Prédio Central 1 - Av. Prof. Lúcio Martins Rodrigues, 443 - Butantã, São Paulo, SP, BRASIL, 05508-020.
} 
This article analyzes the concept of management in education and discusses the main results from a first exploratory approach to the situation of subjects with topics on management and entrepreneurship in the context of teacher education courses. The quantitative and qualitative research presented here conducted a statistical survey analyzing the curriculum of Pedagogy, Language, Arts and Physical Education of the State of São Paulo, as well as the ENADE Proof issues relating to management and entrepreneurship topics such courses. The results indicate the lack of disciplines that deal with the theme of Management and Entrepreneurship in these courses, both with regard to theoretical training as the lack of systematic stimulation of skills required to manage cultural or educational projects. As a final consideration, it is suggested to implement these courses in a discipline possessing such knowledge of the term Management and Entrepreneurship, and increase the number and complexity of the issues of Management and Entrepreneurship in ENADE the evidence corresponding to these courses.

Keywords: Management and Entrepreneurship. Formation of Teachers. Higher Education Institutions. 


\section{INTRODUÇÃO}

O termo gestão tem sua origem na área da Administração de Empresas. Contudo, com a evolução das escolas de gestão dos Estados Unidos o termo passou a ser utilizado também em outras áreas do conhecimento e, como consequência, a ser dominado por psicólogos, sociólogos, biólogos, matemáticos, estatísticos etc; tornando-se, assim, interdisciplinar (DIAS, 2002).

Embora não haja uma definição única e universalmente aceita para gestão, há consenso de que se trata do processo de coordenar tarefas e atividades de maneira que sejam desempenhadas de forma eficiente e eficaz tendo em vista determinado objetivo previamente estabelecido. Para dar conta disso, os princípios básicos da gestão são divididos em quatro: planejamento, organização, liderança e controle. No planejamento determina-se o plano de ação (estratégia) para cumprir os objetivos a serem alcançados, por meio do desenvolvimento de planos para integrar e coordenar as atividades. $\mathrm{O}$ princípio da organização permite estabelecer as relações entre os departamentos/setores de uma instituição com vistas aos objetivos traçados. É nesse ponto que são definidas as tarefas que devem ser efetuadas, quem as executará, como serão agrupadas, quem reportará a quem e onde as decisões serão tomadas. O princípio da liderança está ligado à criação de uma atmosfera que seja capaz de auxiliar e motivar os colaboradores a atingir os objetivos. Por fim, o princípio do controle significa estabelecer, medir e avaliar o desempenho das atividades face aos objetivos traçados, de forma a assegurar que as tarefas estejam sendo realizadas em conformidade com o esperado (AFONSO, 2007).

Esses princípios básicos da gestão foram elaborados dento da área da Administração e acabaram sendo adotados por diversas outras áreas num primeiro momento, sendo, posteriormente, adaptados às diversas realidades e contextos como é o caso na Educação.

Um traço fundamental da Educação é seu caráter de processo complexo que envolve inúmeros atores, pessoas físicas e jurídicas e, além disto, trata-se de um processo que pode acontecer em espaços acadêmicos formais e não formais, ou seja, um contexto singular.

$\mathrm{Na}$ educação, fazendo um breve relato histórico, durante muitos anos as escolas adotaram o modelo de administração baseado nos princípios de Taylor (considerado um dos pais da Administração) que predominava na sociedade industrial no início do século $\mathrm{XX}$, e que tinha como principais características ser centralizadora e hierarquizada. Segundo Freitas (2000), nesse modelo, a teia administrativa tinha a forma de pirâmide, cujo topo hierárquico era legitimamente ocupado pelo chefe detentor de todo poder de decisão e de mando, e os demais membros, distribuídos por especializações, eram executores de ordens e planejamentos. Seguindo essa lógica, na base da pirâmide do sistema educacional, cumprir planejamentos pedagógicos exógenos à sua realidade escolar constituía o principal alvo das atenções de diretores e professores, conforme a expectativa administrativa de seus superiores.

Ainda segundo Freitas (2000), foi a abertura política nacional dos anos 1980 que deu espaço para que a educação passasse a ser pensada a partir da realidade escolar. 
Neste novo cenário, as novas políticas públicas passaram a contemplar a descentralização administrativa e uma gestão escolar participativa de cunho democrático, com o foco na realidade da escola e de suas comunidades escolar e local. Até o fim do século XX várias mudanças na política da administração da educação brasileira aconteceram. O discurso legal e político tomou a direção de proporcionar mais participação da sociedade, inclusive com responsabilidade financeira, e o Estado passou a permitir e incentivar a coexistência de várias formas de gerenciamento escolar, aparentemente mais democráticas.

O termo gestão tomou tal importância e proporção na área educacional, que dos anos 1980 em diante passou a figurar amplamente nos congressos e seminários sobre Educação realizados no Brasil, provocando novas reflexões sobre seu conceito, princípios e a sua aplicação nas escolas brasileiras.

Dessas reflexões resultam constatações como a feita por Silva Junior (apud FREITAS, 2007) de que o uso corriqueiro do termo gestão impregnou o imaginário coletivo e, como consequiência, em determinados segmentos do discurso educacional brasileiro gestão significa gestão empresarial, e tal entendimento leva ao enfraquecimento do significado de gestão educacional e à mercadorização de seus elementos.

Nessa linha, Freitas (2007) entende que o termo gestão aparece na Educação com um significado restrito, sendo geralmente empregado para designar o processo pelo qual se viabiliza determinada política educacional. E apresenta um exemplo desse tipo em publicação da Associação Nacional de Política e Administração Educacional (Anpae), na qual gestão educacional é definida como:

...conjunto de instrumentos para a direção, o gerenciamento e a coordenação das ações concretas previstas nos planos, programas e projetos, para garantir a obtenção dos resultados programados e o atingimento dos objetivos e orientações gerais presentes na política estabelecida. (ALGARTE, 1998, pp.16-17 apud FREITAS, 2007, p.504)

Para Freitas (2007, p.504), nesta definição, "a gestão aparece como intervenção posterior e dependente da política, não resguardando a abrangência semântica atribuída ao termo no momento em que ele se propagou no discurso educacional brasileiro".

Contudo, esse mesmo autor apresenta o uso do termo gestão para designar um processo mais amplo, que abrange a política educacional em suas diversas fases constitutivas (formação de agenda, formulação, implementação, implantação, monitoramento, avaliação). Um exemplo desse uso do termo pode ser visto em Bordignon e Gracindo (2000, p.147 apud FREITAS, 2007, 504), que o utilizam para designar o "[...] processo político-administrativo contextualizado, através do qual a prática social da educação é organizada, orientada e viabilizada". 
Neste sentido, encontramos em Sousa (2001), uma definição de gestão que não nega a origem na Administração, mas propõe a sua contextualização dentro de princípios sociais próprios da Educação.

Gestão é administração, é tomada de decisão, é direção. Relaciona-se com a atividade de impulsionar uma organização a atingir seus objetivos, cumprir sua função, desempenhar seu papel. Constitui-se de princípios e práticas que afirmam ou desafirmam os princípios que as geram. Estes princípios, entretanto não são intrínsecos à gestão como a concebia a administração clássica, mas são princípios sociais, visto que a gestão da educação se destina à promoção humana. (Sousa, 2001, p. 306)

\section{A PESQUISA}

O presente artigo tem origem na pesquisa realizada no ano de 2012 pelo grupo $\mathrm{n}^{\mathrm{o}} 28$ da Fundação Nacional de Desenvolvimento do Ensino Superior Particular (FUNADESP), em parceria com o Instituto de Pesquisas Aplicadas e Desenvolvimento Educacional (IPADE) e a Universidade UniABC-Anahnguera, cujo título é Arte, Cultura e Educação sob uma perspectiva interdisciplinar na formação de professores. Uma pesquisa exploratória documental quanti-quali que teve por objetivos: identificar a participação de disciplinas com temáticas voltadas para a Arte, Cultura e Educação no processo de formação dos docentes; e mensurar a importância destinada a essas áreas nos cursos de formação de professores de Artes, Pedagogia, Letras e Educação Física.

Tal grupo foi coordenado pela pesquisadora Prof. Dr. Sonia R. Albano de Lima, e constituído pelos professores doutores Adriana Clementino, Ana Lucia Nogueira Braz, Felipe Chibás Ortiz e Fernanda Verdasca Botton, além dos bolsistas de IC estudantes da UNIABC - Anhanguera - Unidade III, Gabriel de Jesus Estevam, Juliana Sgarbi Malveze e Tatiana Sayone Namba, substituída pela bolsista Nicole Sofia Hatzis Gomes no mês de agosto de 2012. Contou ainda com a colaboração do aluno Nilton César Gutierres, do curso de Educação Física da UNIABC- Anhanguera, que gratuitamente auxiliou as estagiárias na coleta de dados.

Conforme levantamento efetuado no portal do MEC, foi identificado um total de 623 (seiscentos e vinte e três) instituições de ensino superior (IES) no Estado de São Paulo. Desse montante foram recolhidas apenas as IES que atuavam nas áreas de Pedagogia, Artes (cursos específicos) e Educação Artística (cursos genéricos), Letras e Educação Física, o que correspondeu a um total de 339 IES.

Das 339 IES analisadas, considerou-se para efeito de avaliação, apenas aquelas que possuíam site na internet com matrizes curriculares precisas. A partir da adoção 
deste critério, restaram para avaliação, apenas 213 instituições, conforme representado no gráfico a seguir:

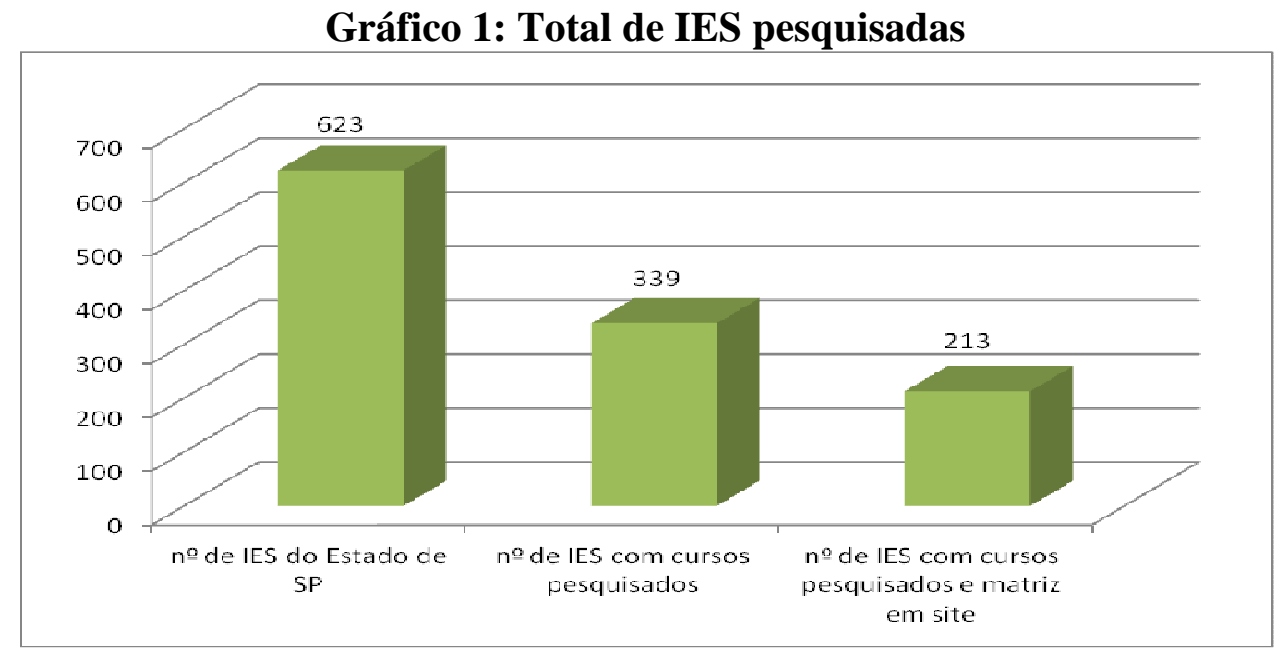

Fonte: Dados da pesquisa.

Na pesquisa realizada, constatou-se a existência de 1089 cursos registrados nas áreas pesquisadas. Contudo, considerando-se os critérios adotados pelo grupo para seleção das IES, foram avaliados apenas 661 cursos, o que corresponde a um percentual de $60,69 \%$ do total de cursos de Pedagogia, Letras, Educação Artística e Artes que existem no Estado de São Paulo. A tabela que se segue especifica a quantidade de cursos em cada uma das áreas avaliadas.

Tabela 1: Total de cursos analisados

\begin{tabular}{|l|c|}
\hline \multicolumn{1}{|c|}{ Área } & Quantidade de cursos \\
\hline Artes & 103 \\
Educação Física & 149 \\
Letras & 206 \\
Pedagogia & 203 \\
Total Geral & $\mathbf{6 6 1}$ \\
\hline
\end{tabular}

Fonte: Dados da pesquisa.

As palavras Arte, Cultura e Educação, objetos da pesquisa, foram denominadas pelo grupo como troncos disciplinares, pois a partir deles estabeleceram-se ramificações de termos e palavras-chaves que direcionaram as análises das disciplinas contidas nas matrizes curriculares dos cursos pesquisados.

\section{Gráfico 2: Troncos disciplinares}




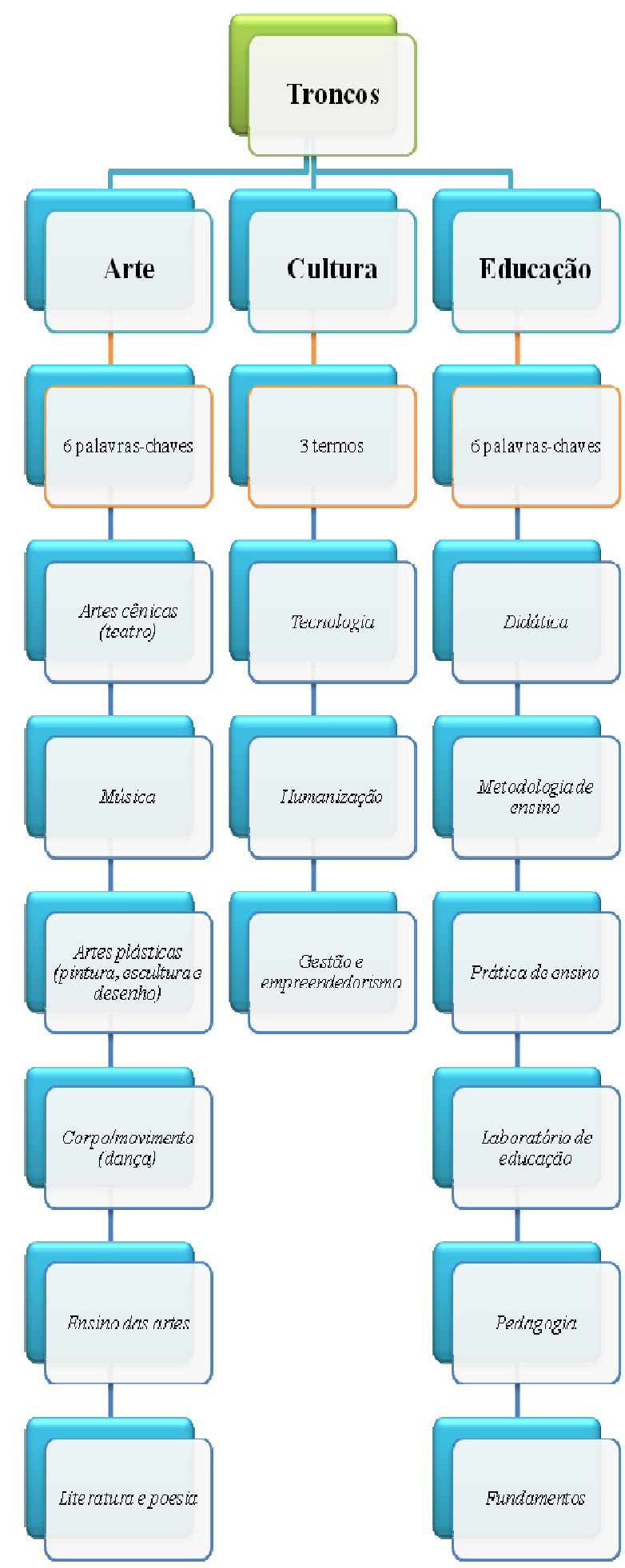

Fonte: Elaborado pelos autores.

Após a indicação dos três troncos disciplinares, houve a subdivisão do tronco Cultura em três termos (Humanização, Tecnologia, Gestão e empreendedorismo), levando em conta a conceituação adotada para a palavra cultura pelo grupo ${ }^{2}$ e a

\footnotetext{
${ }^{2}$ Cultura como uma possibilidade de o homem refletir sobre si mesmo, discernir valores e buscar significados e, trabalhar as Artes como linguagens auxiliares para o desenvolvimento humano.
} 
extensão da sua abordagem. Só então foram elencadas as palavras-chave que nortearam os troncos.

É importante esclarecer que as palavras-chave de todos os troncos e os termos atribuídos ao tronco Cultura foram selecionados, tomando como referencial alguns dos princípios pedagógicos previstos nas Diretrizes Curriculares Nacionais dos cursos verificados, consideradas ainda, a especialidade de atuação de cada pesquisador do grupo. O gráfico 2 contempla a lista de termos e palavras-chaves dos três troncos disciplinares.

Focando especificamente no termo Gestão e Empreendedorismo do Tronco Cultura, objeto deste artigo, nos cursos pesquisados foram elencadas as disciplinas que possuíam palavras-chaves definidas pelo grupo como representante deste termo, entre elas estão: gestão, liderança, empreendedorismo, administração e terceiro setor.

Com a pesquisa do termo Gestão e Empreendedorismo e das palavras-chaves dele derivadas nos títulos das disciplinas dos cursos pesquisados, o grupo buscou identificar se o tema está sendo veiculado nos cursos de formação docente. Nos 661 cursos pesquisados, foram encontradas 666 disciplinas com algumas das palavraschaves.

Aos poucos percebe-se no setor da Educação uma maior compreensão da necessidade da utilização prática do conceito de gestão para se obter melhores resultados educativos com os alunos, assim como para que os graduandos por sua vez obtenham melhores resultados no futuro no exercício das suas profissões. Mesmo assim essa compreensão ainda é imatura e superficial e precisa ser aprofundada.

\section{O TERMO GESTÃO E EMPREENDEDORISMO NOS CURSOS AVALIADOS}

A análise dos dados coletados foi realizada por meio do exame dos sites das Instituições de Ensino Superior (IES), Portal do MEC, Portal Edubrazuca, Mega Portal de Universidades, Portal de Ensino, Portal Guia de Faculdades, Portal Estudantes e Portal Brasil com o propósito de obter informações mais esclarecedoras e consistentes sobre o tema abordado.

A importância do termo Gestão e Empreendedorismo se revela no fato de que nos diversos cursos pesquisados são mencionadas diferentes competências relativas ao mesmo como essenciais na obtenção de resultados positivos para os profissionais desse setor. Por exemplo, nas diretrizes curriculares do MEC para o curso de Pedagogia, se destaca a importância do graduando na gestão de processos educativos e na organização e funcionamento de instituições de ensino (Brasil, 2006).

Os professores de educação física devem saber coordenar, assessorar, liderar e gerenciar equipes multiprofissionais, assim como controlar e avaliar programas e projetos de atividades físicas e recreativas, habilidades estas todas relativas à gestão (Brasil, 2006). 
Também nos cursos de graduação em música, dança e teatro, mesmo que de forma explicita não mencionem essas habilidades, resulta necessário dirigir coletivos de pessoas, sejam eles músicos, bailarinos, atores, etc.

No curso de Graduação em Design também se exige que o graduando tenha habilidades de interagir com especialistas de diferentes áreas, possuir uma visão sistêmica, domínio das diferentes etapas do projeto, assim como da gerencia de produção; competências estas todas que se enquadram dentro do conceito mais atual da gestão.

Com a análise do termo Gestão e Empreendedorismo e das palavras-chaves dele derivadas (Gestão, Administração, Empreendedorismo, Terceiro Setor e Liderança) o grupo buscou identificar qual é o peso que está sendo outorgado à liderança e à tendência a gerir redes de contatos humanos e de outros recursos nos cursos de formação docente.

A seguir faremos uma análise de como se apresentou esse Termo e as respectivas palavras-chaves em cada curso. O objetivo foi identificar se o conceito de gestão e empreendedorismo está sendo abordado nesses cursos e, se este profissional está sendo preparado para as demais atividades relacionadas à educação e formação de pessoas, além da docência efetiva em sala de aula.

\subsection{GESTÃO E EMPREENDEDORISMO NO CURSO DE PEDAGOGIA}

Neste curso foram encontradas 458 disciplinas que apresentaram as seguintes palavras-chaves: gestão, liderança, empreendedorismo, administração, e terceiro setor. Dos 203 cursos de Pedagogia analisados, 201 tinham disciplinas com o termo Gestão $e$ Empreendedorismo. Desses 201 cursos e a partir das palavras-chaves definidas, foram identificadas 458 disciplinas.

Isto pode estar refletindo a crescente atenção que esta se oferecendo nos cursos de Pedagogia ao conceito de Gestão e seus demais derivados ou categorias afins.

\subsection{GESTÃO E EMPREENDEDORISMO NO CURSO DE EDUCAÇÃO FÍSICA}

Dos 149 cursos de Educação Física analisados, 90 tinham disciplinas com o termo Gestão e Empreendedorismo. Desses 90 cursos e a partir das palavras-chaves definidas, foram identificadas 164 disciplinas, sendo: 99 com a palavra administração, 10 disciplinas comempreendedorismo, 55 com gestão e nenhuma com a palavrachave liderança e terceiro setor.

Isto pode ser um reflexo a crescente tomada de consciência dos gestores e coordenadores destes cursos da necessidade de preparar aos seus graduandos como verdadeiros gestores e empreendedores de projetos. Mesmo assim chama a atenção que não apareçam mencionadas as palavras chaves Liderança e Terceiro setor, sendo que 
por natureza própria os projetos que tentem levar a saúde de forma preventiva para a população devem interagir com junto com outros profissionais com o terceiro setor.

\subsection{GESTÃO E EMPREENDEDORISMO NO CURSO DE LETRAS}

Dos 206 cursos de Letras analisados, 30 tinham disciplinas com o termo Gestão e Empreendedorismo. Desses 30 cursos e a partir das palavras-chaves definidas, foram identificadas 32 disciplinas, sendo: 9 com a palavra administração, 4 disciplinas com empreendedorismo, 19 com gestão e nenhuma com as palavraschaves, liderança e terceiro setor.

Este resultado(a pouca menção do Termo Gestão e Empreendedorismo) era de se esperar pela própria natureza do curso, mesmo assim pode se fazer uma ênfase maior na necessidade dos graduandos aprenderem a gerir os processos pedagógicos, mostrando a necessidade atual de que os profissionais do setor transcendam os muros da escola e se integrem com a comunidade, seja de forma presencial ou virtual, liderando projetos culturais associados à letras. .

\subsection{GESTÃO E EMPREENDEDORISMO NO CURSO DE ARTES}

Dos 103 cursos de Artes analisados, 12 tinham disciplinas com o termo Gestão e Empreendedorismo. Desses 12 cursos e a partir das palavras-chaves definidas, foram identificadas 12 disciplinas, sendo: $5 \mathrm{com}$ a palavra administração, 4 disciplinas com empreendedorismo, 3 com gestão, e nenhuma com as palavraschaves liderança e terceiro setor.

Este resultado (a relativa pouca menção do Termo se comparada com as exigências do curso e da prática cotidiana das profissões associadas a este curso) pode ser devido ao desconhecimento dos coordenadores e gestores destes cursos a respeito da utilidade e necessidade dos conhecimentos de gestão para os graduandos desta carreira.

Chama a atenção que sejam menos mencionadas as palavras chaves Liderança e Terceiro setor, sendo que tanto os atores, como os bailarinos e coreógrafos, assim como designers, entre outros profissionais que saem destes cursos irão precisar de competências e habilidades relativas à gestão e liderança de projetos institucionais, formais e em redes não formais de trabalho, integrando diversas profissões e tipos de pessoas. Sabes-se que cada vez mais são requisitados os profissionais destes cursos para participar de projetos em lugares carentes e junto à população.

Tabela 2: Número de disciplinas com as palavras-chaves do termo Gestão

\begin{tabular}{|l|c|c|c|c|c|}
\hline \multirow{2}{*}{ Palavras Chaves } & \multicolumn{5}{|c|}{ Quantidade de Disciplinas } \\
\cline { 2 - 6 } & Pedagogia & $\begin{array}{c}\text { Ed. } \\
\text { Física }\end{array}$ & Letras & Artes & Total \\
\hline Administração & 104 & 99 & 09 & 05 & 217 \\
\hline
\end{tabular}




\begin{tabular}{|l|c|c|c|c|c|}
\hline Empreendedorismo & 10 & 10 & 04 & 04 & 28 \\
\hline Gestão & 341 & 55 & 19 & 03 & 418 \\
\hline Terceiro Setor & 02 & 00 & 00 & 00 & 02 \\
\hline Liderança & 01 & 00 & 00 & 00 & 01 \\
\hline Total & 458 & 164 & 32 & 12 & 666 \\
\hline
\end{tabular}

Fonte: Dados da pesquisa.

\subsection{COMPARATIVO DO USO DO TERMO GESTÃO E EMPREENDEDORISMO NOS CURSOS ESTUDADOS}

A seguir, nos embasando nos resultados do Quadro 2 apresentado acima, faremos uma análise comparativa do Termo Gestão e Empreendedorismo e as palavraschaves a ele associadas para a totalidade dos cursos analisados.

De forma geral podemos dizer que o Termo foi mais utilizado no curso de Pedagogia, em segundo lugar no curso de Educação física e por último nos de Letras e Arte, nessa ordem. O resultado da pouca menção do Termo surpreende no referente aos cursos de Arte, onde se encontram cursos como os de Design, Teatro, Música entre outros, que requerem em alto grau das competências de Gestão e Empreendedorismo. Isto pode estar refletindo a nosso ver a reinante incompreensão do verdadeiro significado e importância dessas competências para a obtenção de resultados positivos no dia a dia dessas profissões por parte dos coordenadores e gestores desses cursos.

É significativo que a palavra mais mencionada em números totais em todos os cursos seja a de Gestão (488), termo mais moderno e que se associa mais ao agir dinâmico e prático do processo de administrar. Isto reflete, a nosso ver, um progresso no olhar dos coordenadores e gestores dos cursos de Pedagogia, Educação Física, Letras e Artes, dado que estão utilizando uma linguagem que está mais de acordo com os tempos e o que se espera deles, assim como dos seus professores e alunos.

A segunda palavra chave mais mencionada é a de Administração (217), termo mais tradicional e associado à parte administrativa e logística dentro dos centros educativos.

A terceira palavra chave em números brutos foi a de Empreendedorismo. Foi realmente pouco mencionada se comparada com as duas primeiras, o que por sua vez pode ser um reflexo da incompreensão da importância de se ter um olhar empreendedor no setor. A palavra empreendedor (entrepreneur) surgiu na França por volta dos séculos XVII e XVIII, com o objetivo de designar aquelas pessoas ousadas que estimulavam o progresso econômico, mediante novas e melhores formas de agir. Mas o conceito "Empreendedorismo" foi popularizado pelo economista Joseph Schumpeter em 1950 (DEGEN, 2006). Mais tarde com Gifford Pinchot (1989) foi introduzido o conceito de Intra-empreendedor, ou seja, de uma pessoa empreendedora, mas dentro de uma organização. Dessa forma não é necessário criar uma nova organização para ser considerado um empreendedor.

Empreendedor não é apenas quem abre um negócio e o faz crescer, senão também aquele que fazendo parte da equipe ou organização de alguém contribui de forma proativa, dinâmica e comprometida, fazendo a mesma crescer (PINCHOT, 1989). 
Serem as menos ou quase praticamente não mencionadas as palavras-chaves Liderança (uma vez) e Terceiro Setor (duas vezes) reflete a situação real do pouco interesse dentro da academia dos cursos de arte e cultura por estes assuntos, sendo que o aprendizado destes tópicos ou palavras chaves é necessário para o desempenho destas profissões. Por isso, os professores e graduandos destes cursos acabam aprendendo a liderar pessoas e gerir projetos do terceiro setor fora do âmbito escolar, participando de forma ativa da gestão de projetos culturais.

A seguir a tabela que descreve os principais resultados obtidos analisando as provas do ENADE para os cursos em questão.

Tabela 3: Cursos analisados por Questões do ENADE que tratam de Gestão e Empreendedorismo

\begin{tabular}{|c|c|c|c|c|c|c|}
\hline Disciplina & Ano & $\begin{array}{l}\text { Total de } \\
\text { questões }\end{array}$ & $\begin{array}{c}\mathbf{N}^{\mathbf{o}} \text { de } \\
\text { questões } \\
\text { objetivas } \\
\text { sobre gestão }\end{array}$ & $\begin{array}{c}\mathbf{N}^{0} \text { de } \\
\text { questões } \\
\text { discursivas } \\
\text { sobre gestão }\end{array}$ & $\begin{array}{l}\mathbf{N}^{0} \text { de questões } \\
\text { interdisciplinares } \\
\text { sobre gestão }\end{array}$ & $\begin{array}{c}\text { Total de } \\
\text { questões } \\
\text { sobre gestão }\end{array}$ \\
\hline Artes visuais & 2011 & 39 & 0 & 0 & 2 & 2 \\
\hline Letras & 2008 & 40 & 1 & 0 & 3 & 4 \\
\hline Letras & 2011 & 45 & 0 & 0 & 1 & 1 \\
\hline Música & 2009 & 40 & 2 & 0 & 3 & 5 \\
\hline Música & 2011 & 39 & 0 & 0 & 2 & 2 \\
\hline Pedagogia & 2008 & 40 & 1 & 0 & 2 & 3 \\
\hline Pedagogia & 2011 & 39 & 0 & 0 & 1 & 1 \\
\hline Teatro & 2006 & 40 & 0 & 0 & 2 & 2 \\
\hline Teatro & 2009 & 40 & 2 & 0 & 3 & 5 \\
\hline Total & & & 5 & $\mathbf{0}$ & 19 & 24 \\
\hline
\end{tabular}

Fonte: Dados da pesquisa.

À exceção do curso de Teatro, pode-se observar certa tendência a diminuir o número das questões discursivas e objetivas sobre o tema de gestão em três dos cursos analisados (Letras, Música e Pedagogia) no ENADE de 2011, se comparados com as provas do ENADE anteriores (anos 2006 e 2009). Tal constatação resulta em preocupação por parte dos pesquisadores, pois pode estar refletindo o divórcio ainda existente entre o discurso e a prática, dado que se declara por parte das instituições de ensino e suas coordenações que desejam construir um ensino mais prático e que permita dar ao aluno ferramentais para mudar a realidade, mas por outro lado não se elaboram os cursos nem se cobra na prova do ENADE questões de gestão e empreendedorismo que são ferramentas para se trabalhar na prática, ajudando a implementar as ideias teóricas na forma de projetos práticos e assim obter os resultados esperados. Este resultado também pode estar mostrando a falta de uma verdadeira visão interdisciplinar na grade curricular desses cursos. 
A falta de questões sobre gestão faz sentir para o aluno uma diminuição do nível de exigência das instituições no referente a esses conteúdos, razão pela qual prestarão menos atenção aos mesmos, provavelmente achando que são menos necessários.

Essa visão limitada pode estar prejudicando a inserção dos graduandos e dos profissionais formados nesses cursos na vida profissional, dado que os conhecimentos de gestão têm um caráter essencialmente prático, direcionados para a projeção, elaboração, implementação e avaliação de conteúdos, ideias e teorias desses cursos na realidade e no cotidiano de cada um.

\section{CONSIDERAÇÕES FINAIS}

Estas deficiências da academia devem ser urgentemente corrigidas dado que se bem a prática ensina, muitas vezes a carência de uma boa base e formação teórica prejudica o bom andamento dos projetos culturais e por outro lado não se estimula o desenvolvimento dessas competências que potencialmente estão presentes nos alunos destes cursos que vão para a prática sem uma bagagem necessária.

A sugestão da implementação de uma disciplina que reúna tais conhecimentos relativos ao termo Gestão e Empreendedorismo é uma das principais recomendações deste estudo. Nestas disciplinas poderiam ser abordados conhecimentos relativos à gestão de projetos culturais em redes formais e não formais de ensino, utilizando tanto o âmbito presencial como virtual, assim como os referentes a gerir diversos tipos de recursos (humanos, financeiros, mercadológicos, tecnológicos, etc.), as etapas que deve ter um projeto cultural, pedagógico e artístico, entre outros conhecimentos atuais sobre como gerir uma sala de aula, instituição ou projeto educativo-cultural.

Também se sugere incrementar o número e complexidade das questões de Gestão e Empreendedorismo nas provas do ENADE correspondentes a estes cursos.

\section{REFERÊNCIAS}

AFONSO, Jorge. Funções e Níveis de Gestão. 2007. Disponível em $<$ http://mymsiad.blogspot.com/2007/11/funes-e-nveis-de-gesto.html $>$. Acesso em: 20/10/2011.

BRASIL. Decreto 5622, de 19 de dezembro de 2005. Regulamenta o art. 80 da Lei $\mathrm{n}^{\mathrm{o}}$ 9.394, de 20 de dezembro de 1996, que estabelece as diretrizes e bases da educação nacional. Disponível em <www.planalto.gov.br/ccivil_03/Ato20042006/2005/Decreto/D5622compilado-htm> Acesso em 28 de agosto de 2012.

BRASIL, Resolução CNE/CP n. 1, de 15 de maio de 2006. Institui Diretrizes Curriculares Nacionais para o Curso de Graduação em Pedagogia, licenciatura. Diário Oficial da União, Brasília, 16 de maio de 2006, Seção 1, p. 11.

DEGEN, Ronald. e MELLO, Álvaro Augusto. O Empreendedor: Fundamentos da iniciativa Empresarial. São Paulo: McGraw-Hill, 2006. 
DIAS, Emerson de P. Conceitos de Gestão e Administração: Uma visão crítica. In: Revista Eletrônica de Administração - Facef, v. 01, ed. 1, jul./dez. 2002. Disponível em <http://www.facef.br/rea/edicao01/ed01_art01.pdf $>$. Acesso em: 10/10/2011.

FREITAS, Dirce Nei Teixeira de. Avaliação e gestão democrática na regulação da educação básica brasileira: uma relação a avaliar. In: Educação \& Sociedade, Campinas, vol. 28, n. 99, mai/ago. 2007. Disponível em < http://www.scielo.br/pdf/es/v28n99/a11v2899.pdf>.

FREITAS, Katia Siqueira de. Uma Inter-relação: políticas públicas, gestão democráticoparticipativa na escola pública e formação da equipe escolar. In: Em Aberto, Brasília, v. $17, \quad$ n. $72, \quad$ p. 47-59, fev./jun. 2000. Disponível em <http://www.crmariocovas.sp.gov.br/pdf/em_aberto_72.pdf>.

PINCHOT, Gifford. Intrapreneuring, São Paulo: Harbra,1989.

SOUSA, Sandra. Escola e Empresa: Iniciativas de parceria no Estado de São Paulo. In: FERREIRA, Naura e AGUIAR, Márcia (Orgs.). Gestão da educação: impasses, perspectivas e compromissos, São Paulo: Cortez, 2001, p. 295-316.

\section{WEBGRAFIA}

BRASIL. Portal Ministério da Educação. Disponível em: http://portal.mec.gov.br/index.php

EDUBRAZUCA. Disponível em: http://www.edubrazuca.com.br/\#!/

EDUEAD. Portal de ensino. Disponível em: http:// www.portaldeensino.com.br

PORTAL BRASIL. Diposnível em: http://www.portalbrasil.net/

PORTAL DO ESTUDANTE. Disponível em: http://www.portaldoestudante.org.br/

PORTAL GUIA DE FACULDADES. Disponível em: http://www.faculdades.com.br/guia/

UFSC - UNIVERSIDADE FEDERAL DE SANTA CATARINA. Mega Portal de Universidades. Disponível em: http:// www.cfh.ufsc.br/ pagina/universidades/inj.htm 